\title{
ANÁLISE DE ATAQUES POR CLORETOS EM CONCRETO LEVE ESTRUTURAL COM ARGILA EXPANDIDA
}

\author{
OLIVEIRA, GABRIEL YVES DA SILVA \\ Estudante \\ Universidade Católica de Brasília \\ Distrito Federal; Brasil \\ gabriel.yves87@gmail.com \\ GUEDES, JACIARA FERREIRA \\ Estudante \\ Universidade Católica de Brasília \\ Distrito Federal; Brasil \\ jacy_fg@hotmail.com
}

\author{
FERREIRA, BÁRBARA E. DOS SANTOS \\ Estudante \\ Universidade Católica de Brasília \\ Distrito Federal; Brasil \\ barbaraemilly880@gmail.com
}

\author{
BARBOSA, ELIABE SANTOS \\ Estudante \\ Universidade Católica de Brasília \\ Distrito Federal; Brasil \\ santos01eliabe@gmail.com
}

\begin{abstract}
RESUMO
A ação de cloretos em estruturas de concreto armado é responsável por uma das manifestações patológicas mais recorrentes na construção civil, a corrosão. O aço é atingido através de um processo localizado de corrosão, causando: a redução de sua seção transversal, o desplacamento do concreto e diminuindo a resistência à compressão e a tração do conjunto. Este trabalho tem como objetivo analisar o ataque de cloretos em concreto leve estrutural com argila expandida e em concreto convencional, obtendo-se medições de penetrações em cada corpo de prova moldado. Foram moldados corpos de prova (CPs) para cada traço, 3 de cada traço foram colocados em uma solução aquosa com a presença de cloretos $(\mathrm{NaCl})$ por 28 dias, em ciclos de 7 dias submersos e 7 dias secando, afim de simular um ambiente de alta agressividade, por ataques de cloretos. Os outros CPs de cada traço foram curados e rompidos conforme a NBR 5739:2018 nos intervalos de tempo de 7, 14 e 28 dias de idade, afim de analisar suas respectivas resistência à compressão. Após isso, os CPs foram submetidos a tração por compressão diametral, para que houvesse o rompimento destes, foi então, aspergido uma solução de nitrato de prata para a verificação visual e respectivas medições da penetração de cloretos em cada CP. Verificou-se que os CPs com argila expandida obtiveram valores de penetração de cloretos menores, quando comparada com os CPs convencionais estruturais Palavras-chave: concreto leve, cloretos, estrutural.
\end{abstract}

\begin{abstract}
The action of chlorides in reinforced concrete structures is responsible for one of the most recurrent pathologies in civil construction which is corrosion. Steel is achieved through a localized corrosion process, that causes: reduction in cross section, deflating the concrete and decreasing the compressive strength and traction of the assembly. This work aims to analyze the attack of chlorides in structural lightweight concrete with expanded clay and conventional concrete, obtaining measurements of penetrations in each molded specimen. Specimens were molded for each trace, 3 of each trace were placed in an aqueous solution with the presence of chlorides $(\mathrm{NaCl})$ for 28 days, in cycles of 7 submerged days and 7 days drying, in order to simulate an environment of high aggressiveness, by chloride attacks. The other specimens of each stroke were healed and ruptured according to NBR 5739:2018 at the time intervals of 7, 14 and 28 days of age, in order to analyze their respective compressive resistance. After that, the specimens were submitted to traction by diametrical compression, so that there was disruption of these and then sprinkled a solution of silver nitrate for visual verification and respective measurements of chloride penetration in each specimen. It was found that specimens with expanded clay obtained penetration values of smaller chlorides when compared to structural conventional speciemens.
\end{abstract}

Keywords: lightweight concrete, chlorides, structural. 


\section{INTRODUÇÃO}

A composição do concreto se resume em uma mistura de quatro componentes, que são: agregados, areia, cimento e água, como afirma Battagin (2009): "O concreto é uma mistura homogênea de cimento, agregados miúdos e graúdos, com ou sem a incorporação de componentes minoritários (aditivos químicos)". Dentre os tipos de concreto, têm-se, o concreto simples (não estrutural), que é uma mistura dos quatro componentes que pode ter adição de aditivos e o concreto armado (estrutural), sendo a junção do concreto simples com armadura ou ferro, que eleva a resistência tanto aos esforços de tração como o de compressão. A NBR 6118 (ABNT,2014) conceitua o concreto estrutural como: "O termo que se refere ao espectro complemento estrutural das aplicações do concreto como material estrutural", que pode ser caracterizado por três elementos: $\mathrm{O}$ concreto simples estrutural, elementos estruturais elaborados com concreto que não possui qualquer tipo de armadura, ou que possui em quantidade inferior ao mínimo exigido para o concreto armado; Concreto armado, aquele que depende da aderência entre o concreto e armadura, e nos quais não se aplicam alongamentos iniciais dar armaduras antes da materialização dessa aderência. Concreto protendido, aquele nos quais parte da armadura é previamente alongada, com finalidade impedir ou limitar a fissura e os deslocamentos da estrutura.

Entretanto, como uma forma de acelerar o processo de produção e consequentemente a produtividade dos concretos estruturais, vem crescendo os estudos para concreto estrutural leve, com materiais alternativos ao concreto convencional. Por apresentar uma baixa densidade, o uso do concreto leve reduz o peso próprio que os concretos convencionais, interferindo diretamente na economia final da construção, adicionando-se também a vantagem de ser um produto que tem um bom desempenho como isolante térmico e acústico (HER-YUNG,2009). De acordo com a NBR 8953 (ABNT, 2015), o concreto leve possui uma massa especifica seca inferior a $2000 \mathrm{~kg} / \mathrm{m}^{3}$, enquanto o convencional tem uma massa superior a $2800 \mathrm{~kg} / \mathrm{m}^{3}$. Para que esse concreto seja considerado estrutural, sua resistência tem que ser superior $20 \mathrm{Mpa}$. As aplicações do concreto leve estrutural são em diversas áreas da construção civil, como pontes, edificações préfabricadas e plataformas marítimas.

Por apresentar tais características, os concretos leves têm sido utilizados desde o começo deste século, tanto para fins estruturais como para vedação. A solução é vantajosa quando precisa vencer grandes vãos, como em pontes, lajes e coberturas, pois diminui a carga estrutural de uma obra e possibilita reduzir os custos da fundação, tem um ótimo desempenho térmico, é um isolante acústico e em relação ao concreto convencional o concreto leve é considerado mais durável. Uma das desvantagens é o seu alto custo, e a diminuição da resistência mecânica à compressão. Segundo Rossignolo (2009), essa desvantagem não limita o seu uso, mas tem que ser considerada no projeto. "Para conseguir o mesmo desempenho mecânico do concreto convencional, é preciso redosar o concreto, usando um pouco mais de cimento, o que encarece o produto", afirma.

Nos últimos anos, é cada vez mais comum ver argila expandida no concreto leve estrutural. Em algumas estruturas de concreto como os edifícios de múltiplos andares, o peso próprio é elevado em relação às cargas aplicadas. A redução do peso, com uso de concreto leve, traz melhorias aceitáveis para o desempenho da estrutura (ROSSIGNOLO, 2009). Aqui no Brasil a produção de argila expandida e mais restrita, pois ela e mais utilizada na jardinagem e paisagismo, mas com os avanços da construção civil essa situação vem mudando.

Além da preocupação com a resistência, tem-se uma necessidade de se produzir um concreto mais durável. Pois a durabilidade é bastante questionada, devido ao surgimento de inúmeras deteriorações prematuras. HELEN (1993) os problemas mais frequentes na estrutura de concreto com relação a durabilidade são as corrosões na armadura, responsável por aproximadamente $52 \%$ da manifestação patológica. Inicialmente esse processo se manifesta através de manchas, fissuras, degradação e desplacamento do concreto. Segundo JOHNSON (1969) e MARTIN-PÈREZ et al. (2000), possui como uns dos principais sintomas as fissuras, a degradação e asmanchas.

A corrosão é um dos problemas mais preocupantes, já que compromete a segurança e a capacidade de uso da estrutura. Um dos principais motivos que provocam as corrosões é o ambiente em que a estrutura está estabelecida, o local em que tem uma maior ocorrência, é o ambiente marítimo. No ambiente marítimo, as estruturas de concreto são sujeitas à ataques agressivos de cloreto, encontrados na maresia e na água do mar, resultando na aceleração do aparecimento de manifestação patológica (LICHTENSTEIN,1986).

De acordo com a NBR 6118 (ABNT, 2014), a agressividade do meio ambiente está relacionada às ações físicas e químicas que atuam sobre as estruturas de concreto, independente das ações mecânicas. Mostrando que nos ambientes urbanos a agressividade é moderada enquanto em ambientes marinhos ela é forte. A penetração dos cloretos na camada de concreto se dá através da penetração da água (absorção capilar), que neste caso, quanto menor for os poros, maior será a ação capilar, isso ocorre devido as ações da tensão superficial.

O presente trabalho consiste em utilizar argila expandida como agregado leve para produção de concreto leve estrutural, para fins comparativos com concreto estrutural convencional. Foi analizado a penetração de íons cloretos nos corpos de 
prova moldados com concreto leve e convencional, para compará-los após ciclo de exposição à um ambiente agressivo de solução de $\mathrm{NaCl}$ por 28 dias.

\section{METODOLOGIA}

\subsection{Execução do traço de unitário e dos corpos de prova (CPs)}

Primeiro realizou-se ensaios de caracterização de agregados, os mesmos de origem mineral natural, (nesta etapa inclui-se a areia) foram secos ao ar livre com proteção de intemperes para a retirada da umidade para que posteriormente realizasse a confecção dos corpos de prova, em formato cilíndrico, para os ensaios de rompimento baseada na norma NBR 5739 (ABNT,2018).

Para este estudo foram moldados 18 corpos de prova no total, sendo; 9 para o traço $1 ; 1,28 ; 0,8 ; 0,45$ com adição de $10 \%$ de sílica ativa, 23\% Argila Expandida 0500, 37\% Argila Expandida 1506 e 2\% de superplastificante; e 9 para o traço $1 ; 1,28 ; 1,2 ; 0,45$ com a mesma porcentagem de adição de sílica ativa e superplastificante, 8 corpos de prova (de cada traço) foram utilizados para o ensaio de rompimento a , e 1 corpo de prova (de cada traço) para verificar a massa específica a fim de comprovar que a mesma se encaixaria nos parâmetros de concreto leve estrutural.

Nesta pesquisa utilizou-se cimento Portland CP V, argila expandia tipo 0500, argila expandida tipo 1506 (Figura 1) e agregados.

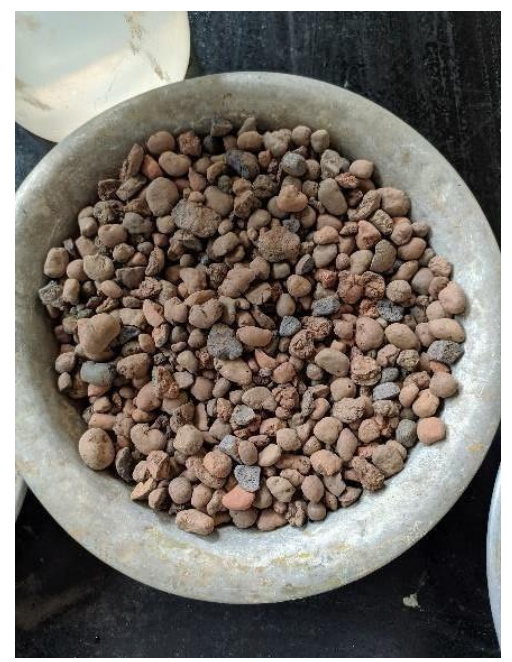

Figura 1 - Argila expandida

\subsection{Resistencia à ação de íons cloreto - Ensaio acelerado}

A aceleração da indução do cloreto nos corpos de prova, foi feito por meio de imersão parcial (Figura 2) dos CPs, em ciclos semanais em solução agressiva, que consistia em água $(\mathrm{H} 2 \mathrm{O})$ e $10 \% \mathrm{de} \mathrm{NaCl}$, posteriormente foram colocados para secagem em temperatura em ambiente. $\mathrm{O}$ ciclo teve duração de 28 dias, variando entre 7 dias com imersão parcial, e 7 dias em secagem em temperatura ambiente.

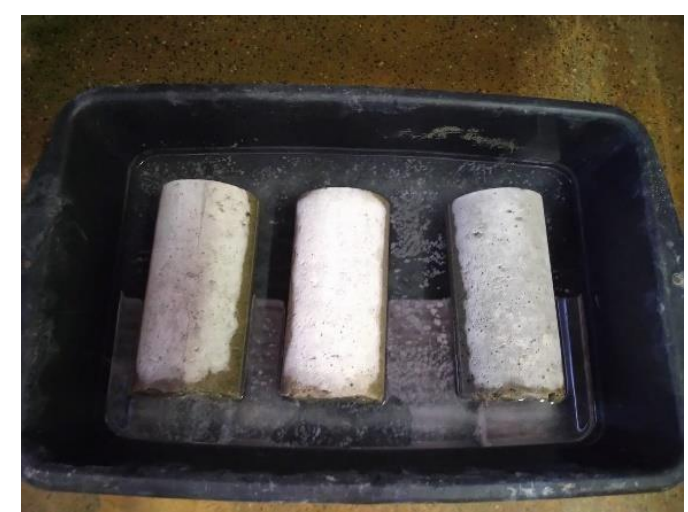

Figura 2 - CPs parcialmente imersos em solução com $\mathrm{NaCl}$

Após os 28 dias, os corpos de prova foram rompidos (Figura 3,4 e 5 ) e aspergidos com nitrato de prata para fazer as devidas averiguações para comprovação da ação do cloreto no concreto. 


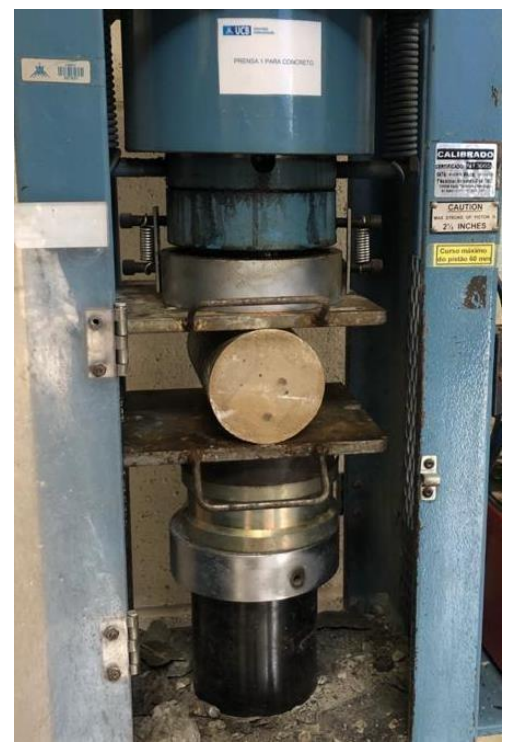

Figura 3 - Corpo de prova sendo rompido por compressão diametral

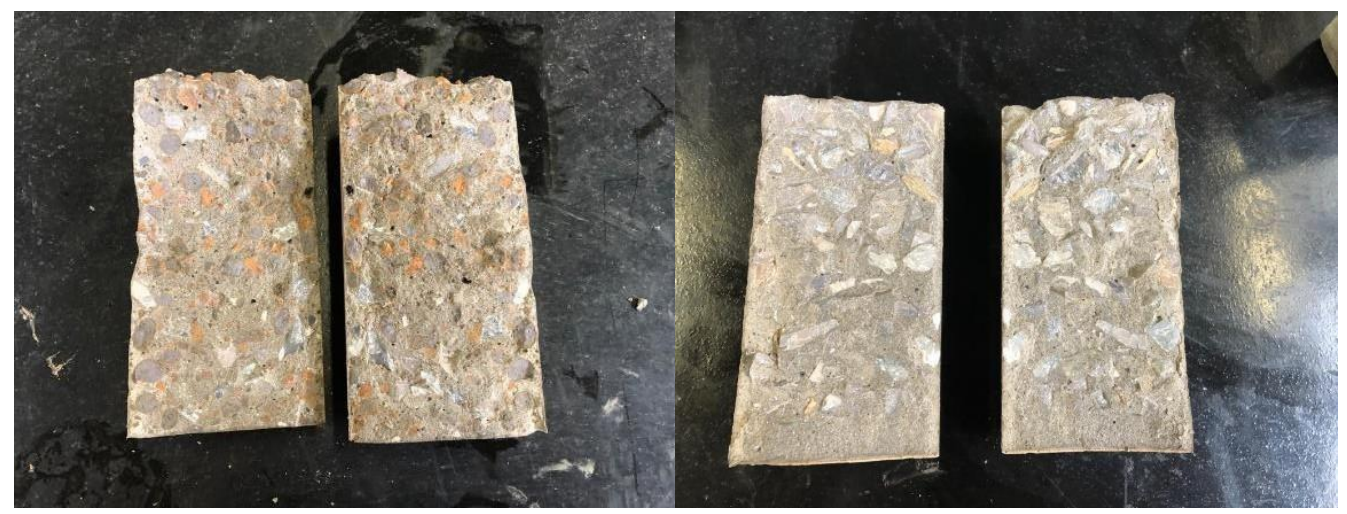

Figura 4 e 5 - Corpos de prova (leve e convencional) após o rompimento

\subsection{Método de avaliação de potencial desempenho a ação de cloreto}

O método colorimétrico por aspersão de nitrato de prata (AgNO3) para avaliação da penetração de cloretos em concreto, Cascudo (1997), conclui que o concreto possui ligações químicas em seu interior entre cloretos e aluminato tricálcico (C3A), que geram cloroaluminato de cálcio (sal de Friedel C3A. CaCl2.10H2O), este tipo de ocorrência pode ser encontrado em como íons livres ou podem sofrer adsorção por meio dos poros do concreto. Caso ocorra a combinação de cloretos, haverá cloretos livres para que as ligações entre os cloretos estejam em equilíbrio, o que possibilita o início da aceleração do processo corrosivo. De maneira qualitativa o método analisa a presença de cloretos livres ou possíveis contaminações por cloreto de maneira visual, através da mudança de cor do concreto (Figura 6 e 7) caso o cloreto alcance a armadura. Para este processo o concreto é submetido a rompimento para que suja uma fratura recente para que seguida ocorra a aspersão da solução de nitrato de prata (AgNO3) com concentração de 0,1 mol/L. A solução possui Íons Ag+- que reagem com os íons do concreto $(\mathrm{Cl}, \mathrm{OH}-)$. Reações químicas do método colorimétrico por aspersão de cloretos ocorrem na zona de cloretos livres, deixando esbranquiçado toda a parte onde ocorre a reação (Equação 1), na zona de cloretos combinados a reação (Equação 2) não alterando a cor do corpo de prova.

$$
\begin{gathered}
\mathrm{AgNO} 3+\mathrm{Cl}-\rightarrow \mathrm{AgCl} \downarrow+\mathrm{NO} 3 \\
2 \mathrm{Ag}++\mathrm{CO}-23 \rightarrow \mathrm{Ag} 2 \mathrm{CO} 3
\end{gathered}
$$



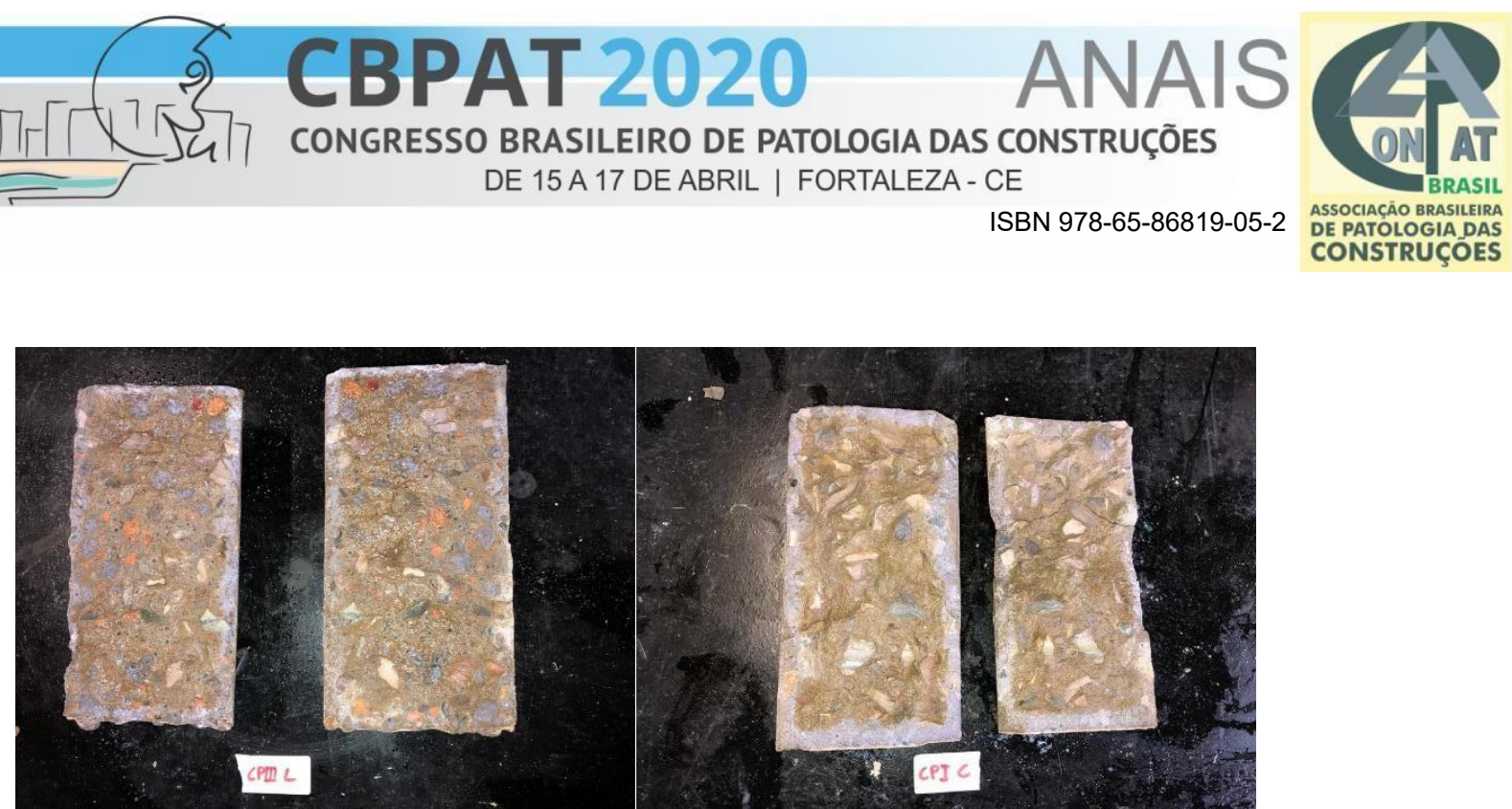

Figura 6 e 7 - Corpos de prova (leve e convencional) após a aspersão de nitrato de prata.

A profundidade de adsorção do cloreto no concreto foi medida com uma regra milimétrica em ambas as partes do CP, em 10 pontos diferentes como mostra a figura 8 .

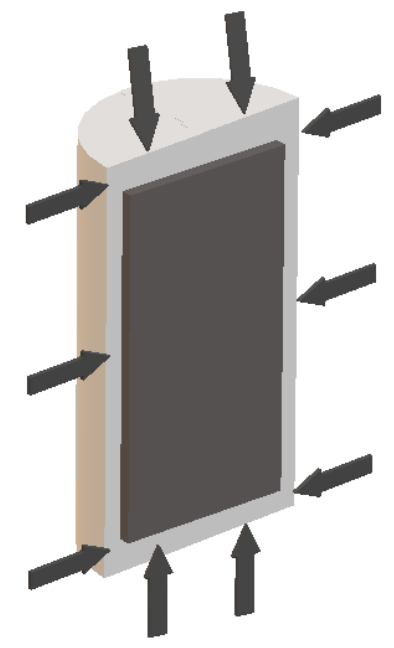

Figura 8- Pontos indicados para retirada de medidas

\subsection{Ensaio de massa específica seca}

Este ensaio é regido pela NBR 9778 (2009), foram obtidos os valores para absorção de água, índice de vazios e massa específica seca, através das equações 3,4 e 5 , respectivamente.

$$
\left(\frac{\text { Msat }-\mathrm{Ms}}{\mathrm{Ms}}\right) * 100
$$

Sendo:

Msat - Massa do corpo-de-prova saturado;

Ms - Massa do corpo-de-prova seco em estufa. 


$$
\left(\frac{\text { Msat - Ms }}{\text { Msat - Mi }}\right) * 100
$$

(Equação 4)

Sendo:

Msat - Massa do corpo-de-prova saturado;

Ms - Massa do corpo-de-prova seco em estufa;

Mi - Massa do corpo-de-prova saturado, imerso em água.

Sendo:

$$
\left(\frac{\mathrm{Ms}}{\mathrm{Msat}-\mathrm{Mi}}\right)\left(\frac{\mathrm{kg}}{\mathrm{m}^{3}}\right)
$$

Ms - Massa do corpo-de-prova seco em estufa;

Msat - Massa do corpo-de-prova saturado;

Mi - Massa do corpo-de-prova saturado, imerso em água.

Assim sendo, o ensaio de massa específica seca visa classificar o concreto em convencional e leve, de acordo com NBR 6118 (ABNT, 2014), onde valores entre $2000 \mathrm{~kg} / \mathrm{m}^{3}$ a $2800 \mathrm{~kg} / \mathrm{m}^{3}$ são identificados como convencionais e valores abaixo de 2000 $\mathrm{kg} / \mathrm{m}^{3}$ são definidos concretos leves.

\section{ANÁLISE DOS RESULTADOS}

Após os corpos de prova moldados conforme NBR 5738 (ABNT, 2015) e deixados em cura úmida por 24h, estes foram levados para solução de $\mathrm{NaCl}$ onde foram deixados pelo tempo de 28 dias, em ciclos de exposição e retirada do ambiente agressivo e posteriormente rompidos a tração por compressão diametral.

As figuras abaixo demonstram a penetração de cloretos nos CP's convencionais CP 1 e CP 2.
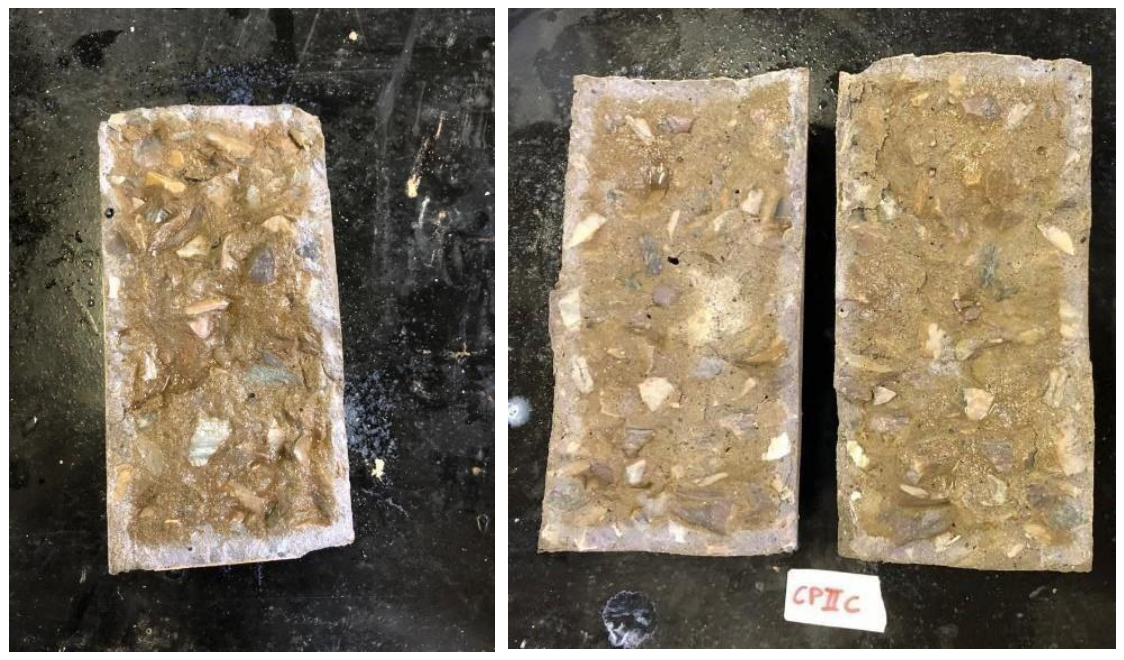

Figuras 9 e 10 - Cp's 1 e 2 convencionais após asperção de nitrato de prata

A tabela abaixo detalha os valores obtidos para penetração média de cloretos nos corpos de prova de concreto convencional e leve.

Tabela 1 - Penetração média CP's convencional

\begin{tabular}{c|c|c}
\hline & Concreto convencional & Concreto leve \\
\hline $\mathrm{CP}$ & Penetração média $(\mathrm{mm})$ & Penetração média $(\mathrm{mm})$ \\
\hline 1 & 11 & 10,75 \\
\hline 2 & 10,25 & 9,25 \\
\hline 3 & 12,75 & 9,25 \\
\hline Média Geral & 11 & 9,25 \\
\hline
\end{tabular}


As figuras abaixo demonstram os corpos de prova de concreto estrutural leve e suas respectivas penetração de cloreto mostradas na tabela 1 . O gráfico 1 representa de forma comparativa a penetração de cloretos nos respectivos CP's convencional e leve.

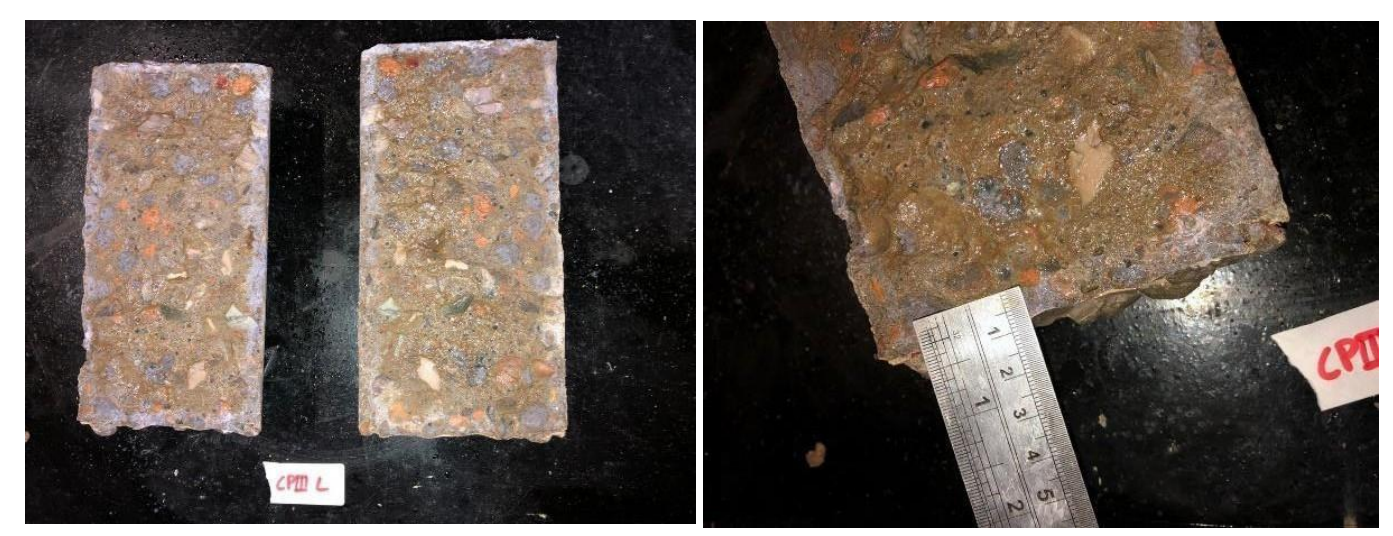

Figuras 11 e 12 - Cp’s 3 e 2 leves após asperção de nitrato de prata

Gráfico 1 - Comparação de penetração de íons cloretos entre os CP's convencionais e leves

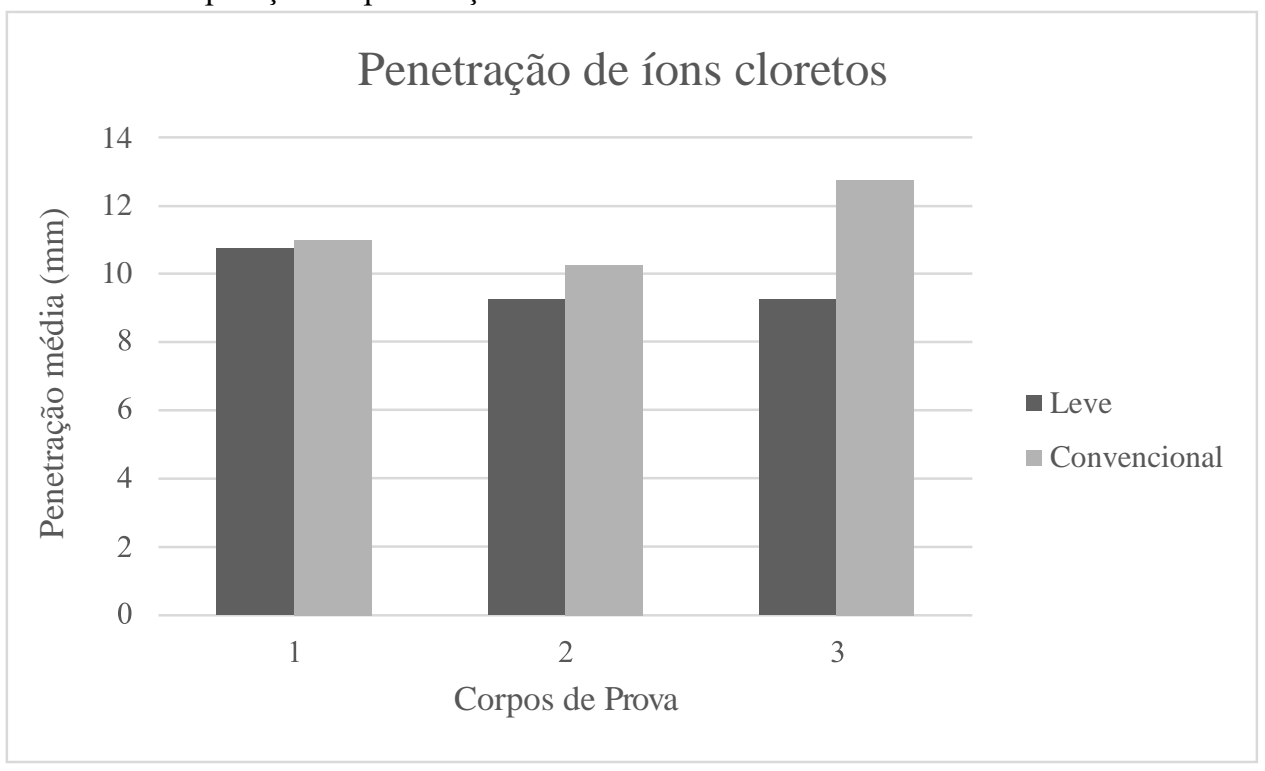

Além do ensaio de penetração de cloretos nos corpos de prova foram executados CP's para respectivo rompimento nos dias de idade 7, 14, 21 e 28 dias. A tabela abaixo mostra os resultados de resistência à compressão dos CP's de concreto estrutural convencional e de concreto estrutural leve. 
Tabela 2 - Resultados de resistências à compressão dos concretos convencional e leve

\begin{tabular}{c|c|c}
\hline & Concreto Convencional & Concreto leve \\
\hline Dias & Resistência à Compressão (Mpa) & Resistência à Compressão (Mpa) \\
\hline 7 & 33,49 & 29,85 \\
\hline 14 & 41,23 & 35,62 \\
\hline 21 & 48,25 & 43,96 \\
\hline 28 & 51,36 & 46,12 \\
\hline
\end{tabular}

De acordo com a NBR 8953 (ABNT, 2015) o concreto leve moldado a partir do traço unitário elaborado pelos autores pôde ser classificado como concreto leve estrutural.

Os valores obtidos para absroção de água, índice de vazios e massa espcífica seca de cada tipo de concreto estão apresentados nas tabelas abaixo. Foi utilizado as equações 3, 4 e 5, respectivamente conforme determina a NBR 9778 (2009).

Tabela 3 - Resultados de absorção de água, índice de vazios e massa específica seca.

\begin{tabular}{c|c|c|c}
\hline \multicolumn{2}{c|}{ Convencional } & \multicolumn{2}{c}{ Leve } \\
\hline Absorção de água $(\%)$ & 3,84 & Absorção de água & 3,13 \\
\hline Índice de vazios $(\%)$ & 8,64 & Índice de vazios $(\%)$ & 5,68 \\
\hline Massa específica seca $\left(\mathrm{kg} / \mathrm{m}^{3}\right)$ & 2248,17 & Massa específica seca $\left(\mathrm{kg} / \mathrm{m}^{3}\right)$ & 1817,06 \\
\hline
\end{tabular}

De acordo com Helen (1993) as manifestações patológicas relacionadas à corrosão na armadura representam mais de metade dos problemas encontrados em estruturas de concreto armado. O concreto leve estrutural produzido pelos autores reforça a viabilidade e o custo benefício de se empregar argila expandida como agregado na produção de concretos leves estruturais, especificamente se tratando de durabilidade das estruturas de concreto.

O trabalho evidenciou pontos positivos do concreto leve estrutural com argila expandida, onde o traço dosado apresentou valores de resistência à compressão próximos aos valores do concreto estrutural convencional, mantendo uma massa específica seca, relativamente, menor quando comparado com o mesmo. Além disso, o CLE (Concreto leve estrutural) apresentou índices de vazios e absorção de água menor do que o concreto convencional, evidenciando sua viabilidade no emprego do mesmo em estruturas que possuem constante contato com água e forte ataque de íons cloreto, ambientes marítimos, onde, estes ambientes aceleram o aparecimento de manifestações patológicas nas estruturas de concreto armado LICHTENSTEIN (1986).

\section{CONCLUSÃO}

Portanto, de acordo com os resultados obtidos, observou-se que o concreto leve estrutural apresentou uma maior resistência a penetração dos cloretos quando comparado ao convencional, apesar dos valores de índice de vazios e absorção de água serem próximos, o concreto leve estrutural obteve melhor desempenho no quesito absorção de água e índice de vazios. Nos ensaios houve uma diferença um pouco mais significante com o concreto estrutural leve obtendo um valor de índice de vazios e absorção de água iguais a 5,68\% e 3,13\%, respectivamente e do concreto estrutural convencional iguais a 8,64\% e 3,84\%, respectivamente. De acordo com Kumayama (2014) minimizando a porosidade, diminui-se a percolação de umidade, dificultando a penetração de íons e de elementos agressivos no concreto.

Porém, apesar do concreto leve apresentar níveis de penetração menores, o mesmo apresentou uma resistência à compressão menor que a do convencional, como esperado. Portanto, deve-se utilizar o concreto leve estrutural em situações específicas que buscam não só um bom desempenho, ainda que inferior ao convencional, em relação à sua resistência à compressão, mas também à durabilidade da estrutura, Angelin et al. (2014) e uma resistência maior a penetração de agentes externos que prejudicam a estrutura da edificação.

O concreto leve apresenta uma durabilidade maior se comparado ao convencional, devido a sua absorção de agua ser inferior a do convencional, o que indica que as fissurações presentes no concreto leve são menores que no convencional, além disso o pó que fica aderido na superfície da argila apresenta propriedades pozolânicas, isso faz com que haja uma zona de transição mais homogênea, fazendo com que a durabilidade do concreto aumente em relação a do convencional, MORAVIA (2007). 


\section{REFERÊNCIAS}

ASSOCIAÇÃO BRASILEIRA DE NORMAS TÉCNICAS. NBR 6118: projeto de estruturas de concreto: procedimento. Rio de Janeiro, 2014. 15p.

ALVES, Helton Gomes; NERI, Kátya Dias; VILAR, Eudésio Oliveira. Estudo mecânico de concretos atacado por cloreto e sulfato. Universidade Federal de Campinas Grande- UFCG. Disponível em: < https://www.editorarealize.com.br/revistas/enect/trabalhos/Poster_175.pdf >. Acesso em: 17 dez. 2019.

ANGELIN, A.F.; LINTZ, R.C.C.; BARBOSA, L.A.G. Studies of Mechanical Properties and Absorption of Lightweight Concrete with Brazilian Expanded Clay. Advanced Materials Research (Online), v. 742, p. 231-236, 2013.

ANGELIN, A.F.; LINTZ, R.C.C.; BARBOSA, L.A.G. Concreto leve estrutural - Desempenhos físicos, térmicos, mecânicos e microestruturais. Repositório Unicamp (Online), p. 77, 2014.

ANGELIN, Andressa Fernanda; LINTZ, Rosa Cristina Cecche; BARBOSA, Luisa Andreia gachet. Uso da argila expandida e sílica ativa no melhoramento dos desempenhos mecânicos, físicos e térmicos de concreto leves estruturais. SCIELO. Rio de Janeiro, 2017. Disponível em: < http://www.scielo.br/scielo.php?script=sci_arttext\&pid=S1517-70762017000500434>. Acesso em: 18 dez. 2019.

BOGAS, J.A.; GOMES, A; PEREIRA, M.F.C. Self-compacting lightweight concrete produced with expanded clay aggregate. Construction and Building Materials, p. 1013-1022, 2012.

BRASIL ATEX, a fôrma da laje. Concreto leve: tipos, benefícios e desvantagens. Disponível em: < https://www.atex.com.br/blog/tecnologia-da-construcao/concreto-leve-beneficios-e-desvantagens/>. Acesso em: 18 dez. 2019.

CINEXPAN, Argila expandida. Concreto leve estrutural diminuição significativa de custos de fundação. Disponível em: < https://www.cinexpan.com.br/concreto-leve-estrutural.html>. Acesso em: 18 dez. 2019.

CONCREBRAS, $\mathbf{O}$ concreto do Brasil. Concreto leve estrutural. Disponível em: < http://www.concrebras.com.br/solucoes-em-concreto/concreto-leve-estrutural/>. Acesso em: 18 dez. 2019.

FONSECA, Caio Rhodolfo Lima. Determinação da profundidade de penetração de cloreto por aspersão de nitrato de prata em estrutura de concreto- estudo de caso. 2017. 73 f. TCC (graduação) - Curso de Engenharia e Ambiental. Universidade Federal da Paraíba, João Pessoa. 2017.

MORAVIA, G.W. Influência de parâmetros microestruturais na durabilidade do concreto leve produzido com argila expandida. Repositório UFMG, p.166-168, 2007.

GOLEWSKI, G.J.; SADOWSKI, T. An analysis of shear fracture toughness KIIc and microstructure in concretes containing fly-ash. Construction and Building Materials, p.207-214, 2014.

KUMAYAMA, Rosemarie. Estudo da viabilidade do emprego do pó de mármore para produção de concreto autoadensável e substituição parcial dos agregados por pérolas de poliestireno expandido (EPS). 2014. $111 \mathrm{f}$. Dissertação (mestrado) - Universidade Estadual Paulista Júlio de Mesquita Filho, Faculdade de Engenharia de Ilha Solteira, 2014. Disponível em: 〈http://hdl.handle.net/11449/111145>.

MAPA, da obra. Concreto leve: conheça tipos e indicações. Disponível em: < https://www.mapadaobra.com.br/inovacao/concreto-leve-conheca-tipos-e-indicacoes/>. Acesso em: 18 dez. 2019. 
MAZER, W; MACIOSKI, G; SOT, N. Penetração de ions cloreto em estruturas de concreto armado. COBQ, Congresso brasileiro de engenharia química. Florianopolis, p. 1-7. 19 e 22, out 2014.

PEREIRA, E.; RESENDE, A.; MEDEIROS, M. H. F.; MENEGHETTI, L. C. Ensaio acelerado por cloreto: efeito da sílica ativa, relação água/ aglomerante e espessura de comprimento do concreto. SCIELO. São Paulo, 2013. Disponível em : < http://www.scielo.br/scielo.php?pid=S1983-41952013000400004\&script=sci_arttext\&tlng=pt>. Acesso em: 18 dez. 2019.

ROSSIGNOLO, João. Concreto leve de alto desempenho modificado com sb para pré-fabricado esbeltos-dosagem, produção, propriedade e microestrutura. 2003. 197 f. Tese (doutorado). Universidade de São Paulo, São Paulo. 2003.

ROSSIGNOLO, J. A. Concreto leve: produção, propriedades, microestrutura e aplicações. Pini. São Paulo. Dez 2009.

SCOBAR, Renan Luna. Concreto leve estrutural: substituição do agregado graúdo convencional por argila expandida. 2016. 46 f. TCC (Graduação) - Curso de Engenharia Civil. Universidade Tecnológica Federal do Paraná, Campo Mourão, 2016.

SIQUEIRA, M. V; SANTOS, A. M; AQUINO, J. T; MOTA, J. M. F. Análise de carbonização e corrosão por íons cloreto em uma passarela da zona oeste do Recife. COONPAR, Conferencia nascional de patologia e recuperação de estruturas. Recife, p. 1-11. 30 e 31, ago 2017. 